Research Article

\title{
A Stress Measurement Method for Steel Strands Based on LC Oscillation
}

\author{
Dongjun Chen, ${ }^{1,2}$ Benniu Zhang $\mathbb{D D}^{1}{ }^{1}$ Xingxing Li, ${ }^{1}$ Chong Tu, ${ }^{1}$ Can Yuan, ${ }^{1}$ Wenzhao Li, \\ Zhixiang Zhou, ${ }^{1}$ and Zongbao Liang ${ }^{1}$ \\ ${ }^{1}$ Chongqing Jiaotong University, Chongqing 400074, China \\ ${ }^{2}$ CSCEC Xinjiang Construction \& Engineering (Group) Co., Ltd., Urumchi 830000, China
}

Correspondence should be addressed to Benniu Zhang; benniuzhang@gmail.com

Received 9 June 2017; Accepted 18 October 2017; Published 17 January 2018

Academic Editor: Antonino Squillace

Copyright ( 2018 Dongjun Chen et al. This is an open access article distributed under the Creative Commons Attribution License, which permits unrestricted use, distribution, and reproduction in any medium, provided the original work is properly cited.

\begin{abstract}
The prestress loss is one of the main factors affecting the safety of prestressed concrete structure. While the detecting signals like sound and light are difficult to spread in steel strands, there is no effective method for prestress detection of the bonded prestressed steel strands in existing structures yet. In this paper, taking into consideration that the electromagnetic oscillation characteristic can make the signal propagate effectively on the bonded prestressed steel strands, a nondestructive prestress detection method based on the electromagnetic effect to detect oscillation frequency is proposed. In a detection circuit, the steel strands are simulated as an inductance component, in which an induced electromagnetic signal passes through the steel strands to form resonance. And then, a frequency meter is used to detect the oscillation frequency of the resonant circuit. The oscillation frequency is supposed to have relationship with the prestress loading on the steel strands. A section of steel strands with a length of $1.2 \mathrm{~m}$ is adopted to test the correlation of stress and oscillation frequency. Both the theoretical and experimental results show that the resonant frequency of the circuit decreases with the increase of the stress of the strand and is linear in a certain range.
\end{abstract}

\section{Introduction}

Prestressed concrete structures are widely used in civil engineering and hydraulic engineering because of their advantages of reducing deformation, improving bearing capacity and cracking resistance. However, the stress relaxation of prestressing tendons, the occurrence of cracks and shrinkage of concrete, and the deformation of anchorages result in loss of prestress. This will decrease the service life of the structures. Therefore, it is important to detect the health status of the prestressed structure at regular intervals.

The expression of the new analytical model $[1,2]$ is established to estimate the stress distribution of the prestressing tendon, which may have a very important influence on nondestructive detection. A series of studies [3-8] show that the performance of prestressed concrete structures will be affected by the prestressed reinforcement corrosion and crack propagation. Under the cyclic loading, the cracks of the prestressed structure will further expand. And it will reduce the stiffness of the concrete structure. Saiedi et al. [9] have tested the performance of three 13-year-old concrete T-beams in the low-temperature environment. Their results show that the prestressed structures which were exposed to low temperature may reduce the strength by about $19 \%$. Hou et al. [10] have done a series of studies on the mechanical performance of the prestressing tendons at $20-800^{\circ} \mathrm{C}$. In their findings, the strength and stiffness loss of prestressed tendons are slower than those of traditional prestressed steel strands. It can be concluded that the temperature has a great influence on the structure and the steel strand. Therefore, it is necessary to consider the influence of temperature on the prestress detection. The influence of time-dependent prestressed concrete members [11] puts forward an interesting conclusion that the change in the length of the transmission exists in some prestressed loading conditions, and the length of the transmission increases as time goes on. In other words, the prestress will decrease as the time goes by. 
Accordingly, the measurement of the steel strand is representative, and detection of the structure in real time is of great significance. Acoustic emission (AE) [4-6] is also an excellent method to monitor the materials' prestressing, and it uses the characteristics of acoustic information to detect the location and size of an acoustic source. Other studies [12-15] such as the application of a new material (unbonded carbon fiber) and technologies (novel optico-acoustic and sensors on a single optical fiber) in the prestressed concrete have also made some progress.

The vibrating wire strain gauge (VWSG) $[16,17]$ and crack reopening method $[18,19]$ are two kinds of methods to measure the existing prestressed structures. VWSG is a nondestructive technique; however, crack reopening method to detect existing stress is a semidestructive method. And an embedded vibrating beam strain gauge (VBSG) [18] is used in T-beam to discover the existing stresses in prestressing strands. The first natural frequency, static displacement and strain of the concrete are used to calculate the existing stresses. However, the force of the concrete structure is influenced by the embedded gauge, and VWSG and VBSG are easily to be affected by environmental factors such as electromagnetic waves and the vibration of the structure. Owing to the fact that both VWSG and VBSG are embedded in concrete structures, they are consumables and cannot be reused. The data acquisition systems and frequency measurement instruments are also much cheaper than the systems used on VWSG and VBSG. What is more, the test equipment which we design can be reused, and it is convenient to carry and can improve the efficiency of testing personnel.

In practical engineering, the length of the prestressed steel strand is up to tens of meters, while the length of the strand used in the test is only $1.2 \mathrm{~m}$. The reason for this is that the purpose of the experiment is to verify the relationship between the stress and magnetism characteristic in Section 2. The steel strand specimen is equivalent to the force model of the steel strand under the tensile force of the universal testing machine. The model which is used in the test can simulate the real stress state well.

The aim of this study is to measure the stress of existing prestressed structures. Accordingly, an electromagnetic oscillation (EMO) method is proposed. To verify the effectiveness of this method, a series of stress tests by electromagnetic oscillation loading on two ends of the steel strand are implemented in laboratory. The form of the steel strand is similar to the inductance in an LC oscillation circuit. Meanwhile, an EMO circuit is created. It is based on the magnetoelastic effect to measure the electromagnetic oscillation frequency and calculate the stress of prestressed structures. The theory which is deduced in Section 2 can get a comparative result, and the most important is that the experimental data match theoretical derivation well.

\section{Theory and Model}

2.1. Formula Derivation. As shown in Figure 1, the inductance $\mathrm{L}$ in the electromagnetic oscillating circuit is

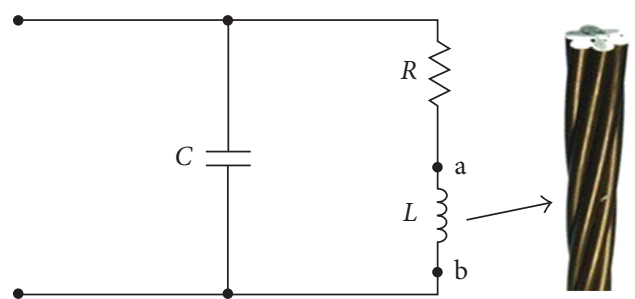

FIgURe 1: Circuit schematic.

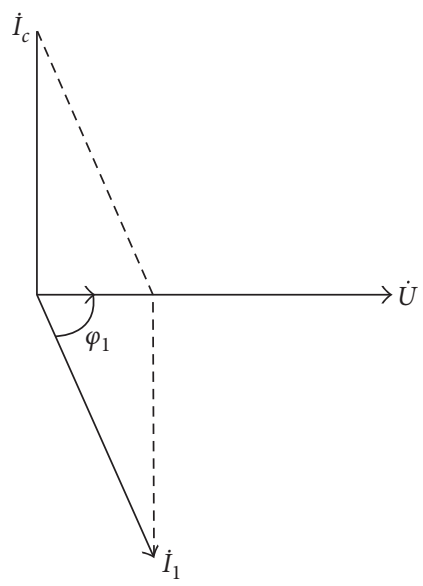

Figure 2: Vector model.

parallel to the capacitance $\mathrm{C}$. When a parallel resonance occurs, the voltage and current are in phase, as shown in Figure 2.

And the vector diagram can be written as

$$
I_{1} \sin \varphi_{1}=I_{c} \text {. }
$$

And it can be drawn from circuit diagram 1 that

$$
\begin{aligned}
I_{1} & =\frac{U}{\sqrt{R^{2}+X_{L}^{2}}}=\frac{U}{\sqrt{R^{2}+(2 \pi f L)^{2}}}, \\
\sin \varphi_{1} & =\frac{X_{L}}{\sqrt{R^{2}+X_{L}^{2}}}=\frac{2 \pi f L}{\sqrt{R^{2}+(2 \pi f L)^{2}}}, \\
I_{c} & =\frac{U}{X_{C}}=2 \pi f C U .
\end{aligned}
$$

Under parallel resonance situation, there is no pure resistance in the circuit, and $\varphi_{1}=90^{\circ}$. Therefore, according to the above formula (1) to (2), the resonant frequency is obtained as follows:

$$
f \approx \frac{1}{2 \pi \sqrt{L C}}
$$

where $L$ is the inductance value of the steel strand, $C$ is the capacitance value of the oscillator, and $f$ is the oscillation frequency.

For conductors, the conductor generates a magnetic field inside and around it when the current passes through it. The magnetic lines of force are concentric closed rings, and the direction is determined by the right-hand rule. As the 


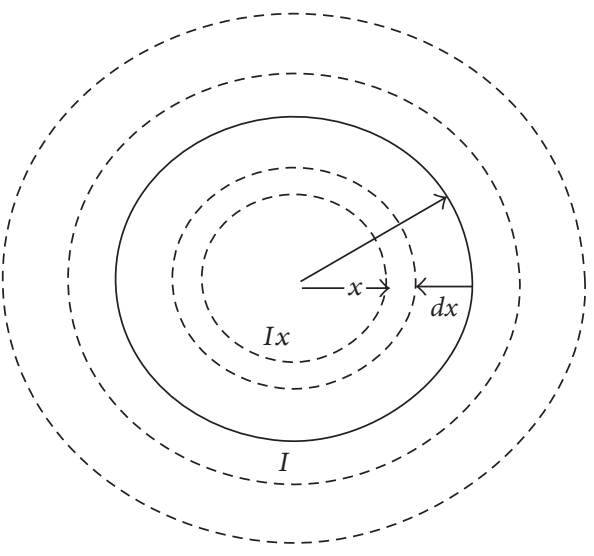

Figure 3: Magnetic field of concentric.

current changes, the flux changes. Assuming $\psi=$ total flux chain, $\phi=\mathrm{flu}$, and $N=$ turn, where the total flux chain $\psi=N \phi=L I$, the inductance can be expressed as

$$
L=\frac{\psi}{I}
$$

As shown in Figure 3, assuming $r$ is the radius of the steel strand intersecting surface, $I$ is the current value passing through it, and a constant $H_{x}$ is the magnetic field intensity of the concentric circular whose radius is $x$, the direction is tangent to the circle.

Assume $I_{x}$ is the electric current of circular cross section with radius $x$. According to the Ampere rules, it can be obtained as

$$
\int_{0}^{2 \pi x} H_{x} \cdot d l=I_{x}
$$

where

$$
H_{x}=\frac{I_{x}}{2 \pi x} .
$$

The inductance of the steel strand is the result of the interaction between the internal flux linkage and the external flux linkage. For the inductance generated by the internal flux linkage, the skin effect is ignored here, and assuming that the current is evenly distributed inside the steel strand, then the current per unit area is equal and can be simply expressed as

$$
\frac{I}{\pi r^{2}}=\frac{I_{x}}{\pi x^{2}}
$$

Substituting $I_{x}$ in (6) leads to

$$
H_{x}=\frac{1}{2 \pi r^{2}} x \text {. }
$$

For magnetic wires, the magnetic permeability is $\mu$, and the magnetic flux density can be expressed as

$$
B_{x}=\mu H_{x}=\frac{\mu I}{2 \pi r^{2}} x .
$$

It can be assumed that the strand is uniform in thickness, for the strand thickness is $d_{x}$, length is $l$, and the magnetic flux differential $d \phi_{x}$ can be expressed as

$$
d \phi_{x}=B_{x} d_{x} \cdot l=\frac{\mu I l}{2 \pi r^{2}} x d x .
$$

This part of the magnetic flux is not around the whole strand but rather part of its cross-sectional area $\pi x^{2}$. Thus, the current density is consistent, and the $\pi x^{2} / \pi r^{2}$ has a magnetic flux linkage that can be written as

$$
d \Psi_{x}=\left(\frac{x^{2}}{r^{2}}\right) d \phi_{x}=\frac{\mu I l}{2 \pi r^{4}} x^{3} d x .
$$

The internal magnetic chain inside the entire steel strand can be obtained by integrating $d x$ from 0 to $r$ :

$$
\Psi_{\text {in }}=\frac{\mu I l}{2 \pi r^{4}} \int_{0}^{r} x^{3} d x=\frac{\mu I l}{8 \pi} .
$$
(4) is

The inductance produced by the internal flux chain of

$$
L_{\text {in }}=\frac{\Psi_{\text {in }}}{I}=\frac{\mu l}{8 \pi} .
$$

For the inductance generated by the external magnetic flux, as shown in Figure 4, it is assumed that the magnetic field strength of the concentric circular magnetic circuit is $H_{x}$ at the external radius $x>r$ of the wire. Since the circle of radius $x$ surrounds the entire current, the current flowing through the circular cross section of radius $x$ is $I_{x}=I$. For nonmagnetic wires, it is assumed that the magnetic permeability is $\mu_{0}$. According to formula (6), the magnetic flux density at radius $x$ can be expressed as

$$
B_{x}=\mu_{0} H_{x}=\frac{\mu_{0} I}{2 \pi x}
$$

Since this part of the magnetic flux surrounds the entire current, the magnetic chain is numerically equal to the magnetic flux. The differential $d \phi_{x}$ of the magnetic flux of the wire whose thickness is $d_{x}$ and length is $l$ can be expressed as

$$
d \Psi_{x}=d \phi_{x}=B_{x} \cdot d_{x} \cdot l=\frac{u_{0} I l}{2 \pi r^{2}} x d x .
$$

The external magnetic chain between $D 1$ and $D 2$ can be obtained by integrating $d \Psi_{x}$ from $D 1$ to $D 2$ :

$$
\Psi_{\text {out }}=\frac{\mu_{0} I l}{2 \pi} \int_{D 1}^{D 2} \frac{1}{x} d x=\frac{\mu_{0} I l}{2 \pi} \ln \frac{D 2}{D 1} .
$$

The inductance between the two external points of the wire can be written as

$$
L_{\text {out }}=\frac{\Psi_{\text {out }}}{I}=\frac{\mu_{0} l}{2 \pi} \ln \frac{D 2}{D 1} .
$$

Thus, the total inductance can be expressed as

$$
L=L_{\text {in }}+L_{\text {out }}=\frac{\mu l}{8 \pi}+\frac{\mu_{0} l}{2 \pi} \ln \frac{D 2}{D 1} .
$$

Since the strand is ferromagnetic, the magnetic permeability is $\mu \gg \mu_{0}$ and the above equation is simplified as

$$
L=\frac{\mu l}{8 \pi}=\frac{\mu\left(l_{0}+\Delta l\right)}{8 \pi},
$$

where $l_{0}$ is the original length and $\Delta l$ is the length increment. 


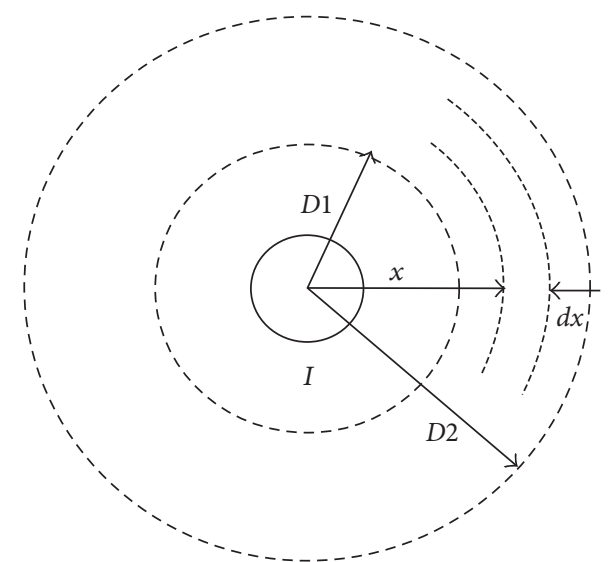

Figure 4: Concentric magnetic field of the external magnetic flux linkage.

According to the simplified constitutive relation of the linear elastic material, the stress value of linear elastic material can be expressed as

$$
\sigma=E \varepsilon=E \frac{\Delta l}{l}
$$

where $E$ is the elastic modulus of steel strand and $\varepsilon$ is the strain.

It can be assumed that if $H$ is the magnetic field intensity and $B$ is the magnetic induction intensity, then the permeability is defined as

$$
\mu=\mu_{r} \mu_{0}=\frac{B}{H}
$$

For the magnetic field strength $H$, the steel strand is equivalent to a long direct current wire, and the magnetic field strength can be expressed as

$$
H=\frac{I}{2 \pi r} \text {. }
$$

As the length changes of the steel strand stretching process are much larger than the cross-sectional area changes, the current size $I$ and radius $r$ are almost unchanged; hence, magnetic field strength can be regarded as unchanged.

The magnetic induction intensity $B$ can be defined as

$$
B=\mu_{0}(H+M) \text {, }
$$

where $M$ is the magnetization and $\mu_{0}$ is the permeability of vacuum.

For the magnetization $M$, in the volume $V$ of the magnet, a large number of magnetic dipoles are contained within this volume, and they all have magnetic moments. It is assumed that the magnetic moment of all the atoms of the steel strand is arranged along the direction of the steel strand; if the magnetic moment of each atom is $m_{0}$, then the size of the total magnetic dipole can be expressed as

$$
m=N m_{0}=\frac{m}{M_{0}} N_{A} m_{0},
$$

where $\rho$ is the average density of the steel strand, $M_{0}$ is the molar mass, and $N_{A}$ is Avogadro's number, and the magnetization can be expressed as

$$
M=\frac{\left(m / M_{0}\right) N_{A} m_{0}}{V} .
$$

Under the effect of stress, when a small length change occurs, the cross-section radius $r$ is almost unchanged, or even it can be ignored, where we assume that the steel strand deformation is $\Delta l$, so the magnetization $M$ size becomes

$$
M=\frac{\left(m / M_{0}\right) N_{A} m_{0}}{V}=\frac{\left(m / M_{0}\right) N_{A} m_{0}}{\pi r^{2} \cdot l}=\frac{\left(m / M_{0}\right) N_{A} m_{0}}{\pi r^{2} \cdot\left(l_{0}+\Delta l\right)} .
$$

Combining (22), (23), and (26), it can be obtained that

$$
\begin{aligned}
\mu & =\frac{\mu_{0}\left((I / 2 \pi r)+\left(\left(m / M_{0}\right) N_{A} m_{0} / \pi r^{2}\left(l_{0}+\Delta l\right)\right)\right)}{I / 2 \pi r} \\
& =\mu_{0}\left(1+\frac{\left(2 m / M_{0}\right) N_{A} m_{0}}{I r\left(l_{0}+\left(\sigma l_{0} / E\right)\right)}\right), \\
L & =\frac{\mu_{0}\left(1+\left(2\left(m / M_{0}\right) N_{A} m_{0} / \operatorname{Ir}\left(l_{0}+\left(\sigma l_{0} / E\right)\right)\right)\right)\left(l_{0}+\left(\sigma l_{0} / E\right)\right)}{8 \pi} .
\end{aligned}
$$

Then combining (3) and (28), the result of formula derivation can be obtained as follows:

$$
f=\frac{1}{2 \pi \sqrt{\left(\mu_{0}\left(1+\left(2\left(m / M_{0}\right) N_{A} m_{0} / \operatorname{Ir}\left(l_{0}+\left(\sigma l_{0} / E\right)\right)\right)\right)\left(l_{0}+\left(\sigma l_{0} / E\right)\right) / 8 \pi\right) \cdot C}} .
$$

2.2. Simulation Result. Substituting $\mu_{0}=4 \pi \times 10^{-7} \mathrm{H} \times \mathrm{m}^{-1}$, $E=1.95 \times 10^{5} \mathrm{MPa}, C=0.1 \mathrm{uF}, l_{0}=19.5 \mathrm{~m}, r=0.005 \mathrm{~m}$, $I=0.1 \mathrm{~A}, \quad m=10 \mathrm{~kg}, M_{0}=55.8 \times 10^{-3} \mathrm{~kg} \times \mathrm{mol}^{-1}, N_{A}=$ $6.02 \times 10^{23} \mathrm{~mol}^{-1}$, and $m_{0}=1.2488 \times 10^{-27} \mathrm{~A} \times \mathrm{m}^{2}$ in (28), it can be obtained that

$$
f=\frac{1000}{2 \pi \sqrt{2.792+5 \times 10^{-7} \sigma}} .
$$

The results are shown in Figure 5.

\section{Experiments}

According to the working principle of the $L C$ oscillating circuit and the limitation of the piston stroke of the universal testing machine, a steel strand specimen whose both ends were insulated and derusted was used to verify the theoretical derivation. Both ends of the prestressed steel strand were clamped in the jaws of the universal testing machine to simulate the anchor zone, and then the axial force is 


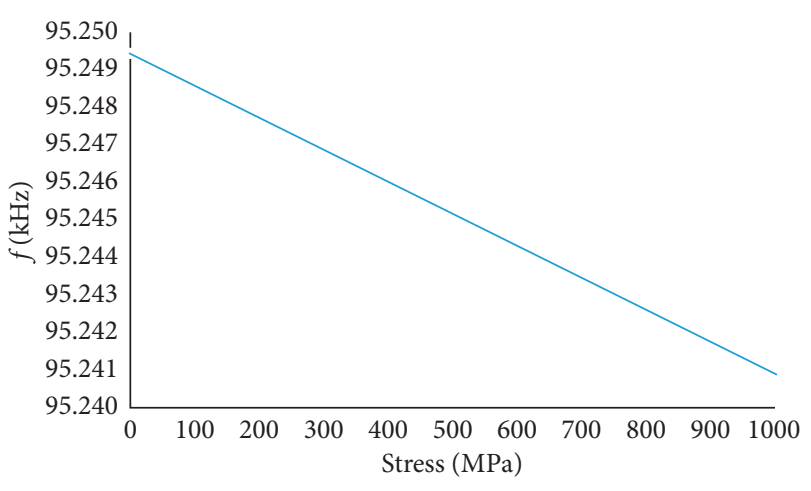

FIGURE 5: Relationship diagram between frequency and stress.

applied to simulate the prestressing of the steel strand after stretching. The deformation of the steel strand, change of oscillation circuit frequency, and stress-strain curve can be observed by applying the force.

3.1. Manufacture of Steel Strand Sample. The steel strand used in the test is a common $1 \times 7$ strand structure whose parameters are shown in Table 1 . The test specimens were made of steel strand with a length of $1.2 \mathrm{~m}$, and both ends of the steel strand were polished with sandpaper. Then, the wire and steel strand were welded by soldering, and it is essential that both ends of the wire's direction should be consistent. After the steel strand firmly welded the whit wire, both ends of the steel strand should be winded with the insulation adhesive tape without leaving gaps. The insulating electrical tape's winding length should be greater than the depth of the universal testing machine to avoid short circuit caused by direct contact. Finally, as the applied load is relatively large, only the electrical tape may cause the steel strand and the universal testing machine to slip which could lead to errors to the experimental data. In order to avoid this situation, both ends of the steel strand were wrapped with coarse insulating electrical tape to ensure the stability of the circuit and the steel strand.

3.2. Brief Introduction of Circuit. An $L C$ oscillator can be built by using the integrated circuit and some peripheral circuits, and the schematic is shown in Figure 6. The $L C$ oscillator module uses MC1648 as the oscillator chip, and the voltage comparator chip uses LM393. In addition, the signal conditioning module uses an LM393 chip. In the schematic, $U 1$ is the oscillator chip, $C 1$ is a resonant capacitor, $C 3$ and $C 4$ are power filter capacitors, and $C 2$ and $C 5$ are the input filter. Besides, $L 1$ is the sum of the inductance of the steel strand and its series, capacitor $R 1$ is the matching impedance, and the measuring range of the digital frequency meter module is between $20 \mathrm{kHz}$ and $100 \mathrm{kHz}$.

3.3. The Process of Experiment. During the experiments, the steel strand is preloaded to $2 \mathrm{kN}$, and the final load is set to $8 \mathrm{kN}$. Such small stress is chosen based on the following reasons: (1) we hope the deformation of the steel strand can be limited in elastic range to test multiple equal cycles; (2) due to the clip limitation of loading, much larger tension may cause relative slippage between the test machine and the strand.

Before the test, the universal testing machine was used to clamp the ends of the insulated steel strand. The wire, which was leaded from both ends of the steel strand, is oriented perpendicular to the surface of the paper. The jaw clamps the $2 / 3$ position of the end of the insulated steel strand to confirm that the steel strand and wire are not directly contacted with the universal testing machine, and the joints were twined by insulating tape. And the structure of the experimental system is shown in Figure 7.

The test procedure is as follows. Firstly, turning on the power supply of the oscillation circuit, the universal testing machine is used to preload the steel strand to $2 \mathrm{kN}$. After three times of loading, it is confirmed that the applied load and the deformation of the steel strand tend to be stable. Finally, the loading rate of $10 \mathrm{~mm} / \mathrm{min}$ is loaded to $8 \mathrm{kN}$. In this period, the frequency meter collects the frequency data once per second, and the collected data are transmitted to the mobile device via bluetooth, and a total of 1 set of test data is collected during the loading process. After the data collection, the tension is unloaded to zero, and the change trend of the frequency is observed during unloading. At the end of a trial, the stress-strain data and corresponding curves are derived from the software which is used in the test. In this way, the same steel strand specimen is loaded 6 times, and a total of 6 sets of data are collected during these processes.

\section{Experimental Results and Data Analysis}

4.1. Experimental Results. Under the same experimental conditions, the 6 loading tests have been completed. The effective data and the calculated data are shown in Table 2. By analyzing the stress-strain curves corresponding to the frequency data in the same time, the data which are corresponding to the nonlinear part of the curve are removed. The median frequency, frequency repeatability error, and frequency standard deviation are calculated by the effective frequency data.

4.2. Data Analysis. In the experiment, the steel strand is in the linear elastic stage. So, the stress of the steel strand increases with the increase of the applied load of the universal testing machine. And the increase of stress will lead to the increase of strain. In general, the load, stress, and strain of the steel strand increase with time.

As shown in Figure 8, the median frequency calculated in Table 2 is in linear regression with time. The stress-strain curve is shown in Figure 9; the blue line indicates the stressstrain relationship between the stretching jaw and the steel strand without sliding, and the red line indicates that, under the same stress, the stress-strain relationship occurs in the case of relative slip.

The following conclusions can be drawn from the analysis:

(1) As can be seen from Loading 1, 2, 5, and 6, the oscillation frequency decreases with the increase of 
TABle 1: Parameters of the steel strand.

\begin{tabular}{lccccccc}
\hline $\begin{array}{l}\text { Structure } \\
\text { of steel } \\
\text { strand }\end{array}$ & $\begin{array}{c}\text { Nominal } \\
\text { diameter of } \\
\text { steel strand, } \\
D(\mathrm{~mm})\end{array}$ & $\begin{array}{c}\text { Nominal area } \\
\text { of steel strand, } \\
S\left(\mathrm{~mm}^{2}\right)\end{array}$ & $\begin{array}{c}\text { Ultimate tensile } \\
\text { strength, } R_{m} \\
(\mathrm{MPa})\end{array}$ & $\begin{array}{c}\text { Maximum } \\
\text { tension, } \\
F_{m}(\mathrm{kN})\end{array}$ & $\begin{array}{c}\text { Nonproportional } \\
\text { extension force, } \\
F_{P 0.2}(\mathrm{kN})\end{array}$ & $\begin{array}{c}\text { Maximum } \\
\text { elongation, } \\
A_{\mathrm{GT}}(\%)\end{array}$ & $\begin{array}{c}\text { Stress relaxation } \\
\text { rate after }\end{array}$ \\
$\begin{array}{c}\text { No less than } \\
\text { No less than }\end{array}$ & $\begin{array}{c}\text { No less than } \\
\text { No more than }\end{array}$ \\
\hline $1 \times 7$ & 15.2 & 139 & 1720 & 241 & 217 & 3.5 \\
\hline
\end{tabular}

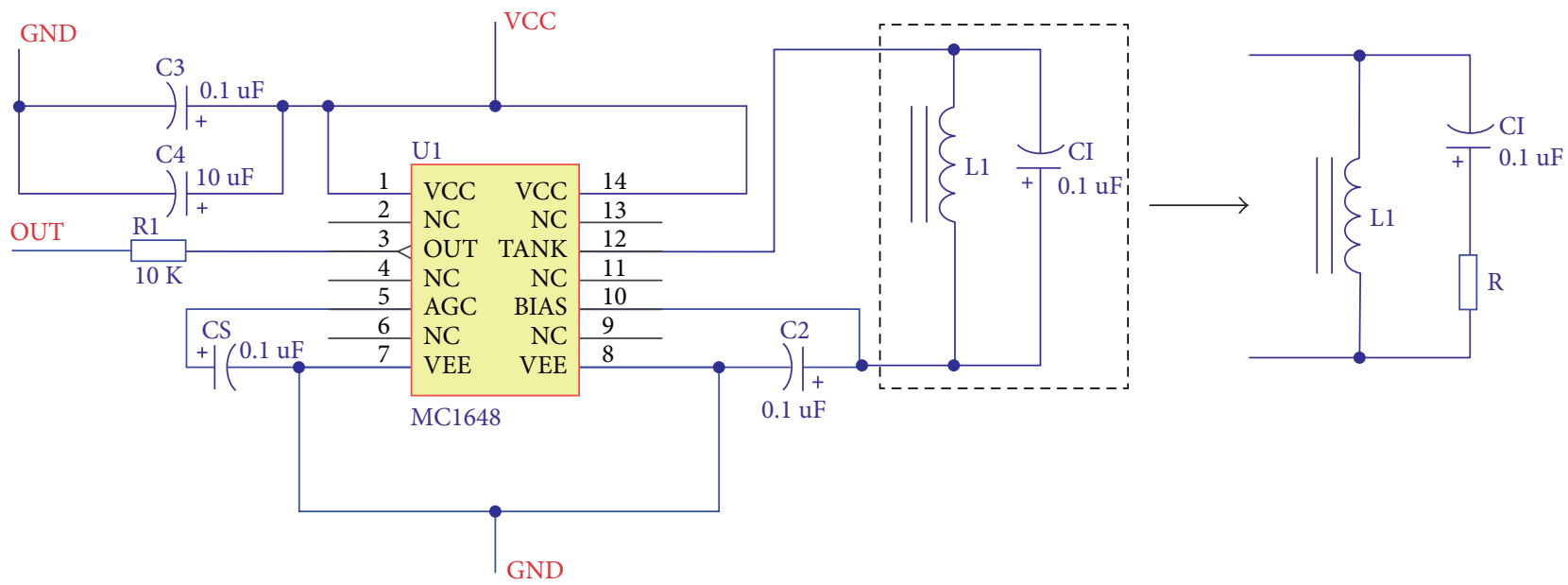

FIgURE 6: Circuit principle diagram.

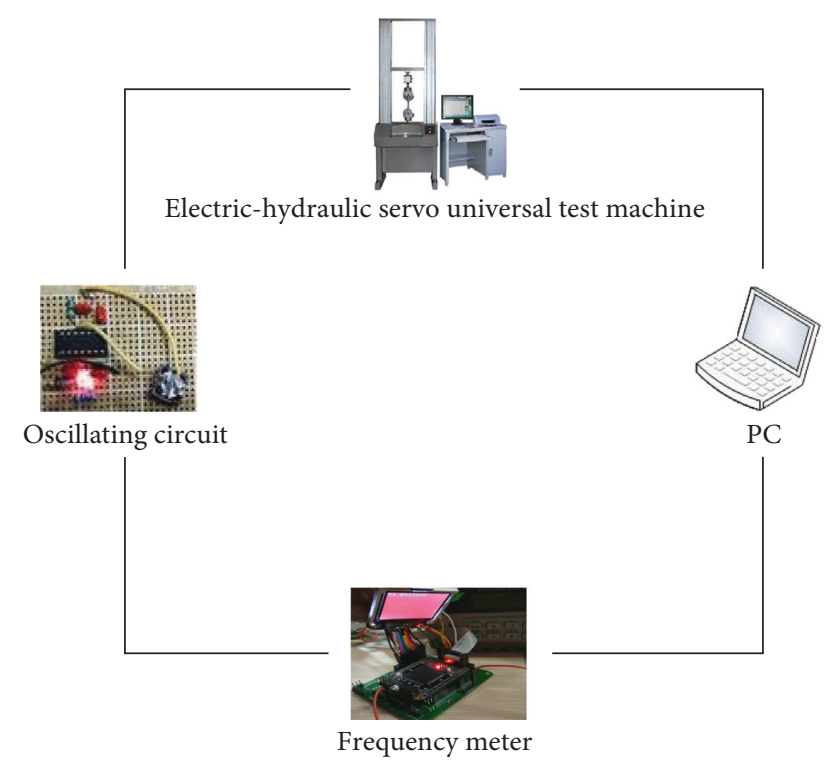

FIGURE 7: The experiment structure diagram.

time, while the stress increases with the increase of time. It can be concluded that the oscillation frequency decreases with the increase of stress and has a linear relationship within a certain range. This is consistent with the theoretical derivation of the second part of the article.

(2) As shown in Loading 3 and 4 of Table 2, in the first 6 seconds, the stress and the oscillation frequency showed a good linear relationship. And with the increase of stress, the oscillation frequency decreased correspondingly. The subsequent 4 seconds have shown the opposite relationship; that is, the oscillation frequency increases with the increase of stress. The reason is that the friction force between the two ends of the universal testing machine and the steel strand is smaller than the tensile force, which results in the relative sliding between the steel strand and the jaw of the universal testing machine.

(3) Figure 9 also shows that, under the same stress, the strain of the steel strand is greater than that of the case without sliding. The tensile force of the steel strand after sliding decreases, and the oscillation frequency increases, which proves that the stress is inversely proportional to the frequency of oscillation. From the data of the frequency meter, the oscillation frequency increases with the unloading of stress. And it is also consistent with the theoretical derivation.

(4) It can be concluded from the analysis of the relationship between the median frequency and time in Figure 8 that, with the increase of the stress in the steel strand, the oscillation frequency decreases and the linear relationship exists in a certain range. It is consistent with the theoretical derivation as well.

(5) The relationships shown in Figure 8 show that the gradient of frequency variation is small in fixed time, and there is a certain relationship with the force rate of the steel strand. The bigger the test force rate is, the bigger the change frequency of the oscillation frequency is and the more obvious the frequency changes are. 
TABle 2: The experimental data.

\begin{tabular}{|c|c|c|c|c|c|c|c|c|c|c|}
\hline \multirow{2}{*}{$\begin{array}{l}\text { Median } \\
\text { strain } \\
\left(10^{-4}\right)\end{array}$} & \multirow{2}{*}{$\begin{array}{c}\text { Median } \\
\text { stress } \\
(\mathrm{MPa})\end{array}$} & \multicolumn{6}{|c|}{ Measurement times } & \multirow[b]{2}{*}{$\begin{array}{l}\text { Repeatability } \\
\text { error }\end{array}$} & \multirow[b]{2}{*}{$\begin{array}{l}\text { Standard } \\
\text { deviation }\end{array}$} & \multirow{2}{*}{$\begin{array}{c}\text { Median } \\
\text { frequency } \\
\quad(\mathrm{kHz})\end{array}$} \\
\hline & & $\begin{array}{l}\text { Loading } \\
1 f(\mathrm{kHz})\end{array}$ & $\begin{array}{l}\text { Loading } \\
2 f(\mathrm{kHz})\end{array}$ & $\begin{array}{l}\text { Loading } \\
3 f(\mathrm{kHz})\end{array}$ & $\begin{array}{l}\text { Loading } \\
4 f(\mathrm{kHz})\end{array}$ & $\begin{array}{l}\text { Loading } \\
5 f(\mathrm{kHz})\end{array}$ & $\begin{array}{l}\text { Loading } \\
6 f(\mathrm{kHz})\end{array}$ & & & \\
\hline 0.7379 & 14.3885 & 74.3009 & 74.2940 & 74.2838 & 74.2754 & 74.2748 & 74.2677 & $0.0170 \%$ & 0.01266 & 74.28277 \\
\hline 1.0146 & 19.7842 & 74.3018 & 74.2926 & 74.2838 & 74.2751 & 74.2746 & 74.2669 & $0.0174 \%$ & 0.01294 & 74.28247 \\
\hline 1.2987 & 25.3237 & 74.3018 & 74.2911 & 74.2828 & 74.2750 & 74.2740 & 74.2656 & $0.0176 \%$ & 0.01309 & 74.28172 \\
\hline 1.6012 & 31.2230 & 74.3010 & 74.2900 & 74.2817 & 74.2748 & 74.2733 & 74.2647 & $0.0175 \%$ & 0.01300 & 74.28092 \\
\hline 1.9111 & 37.2662 & 74.2995 & 74.2889 & 74.2809 & 74.2747 & 74.2720 & 74.2639 & $0.0172 \%$ & 0.01274 & 74.27998 \\
\hline 2.162 & 42.1583 & 74.2995 & 74.2883 & 74.2804 & 74.2742 & 74.2720 & 74.2632 & $0.0173 \%$ & 0.01287 & 74.27960 \\
\hline 2.4682 & 46.6906 & 74.2984 & 74.2881 & 74.2807 & 74.2736 & 74.2712 & 74.2625 & $0.0173 \%$ & 0.01284 & 74.27908 \\
\hline 2.7449 & 50.9353 & 74.2972 & 74.2875 & 74.2809 & 74.2734 & 74.2705 & 74.2619 & $0.0171 \%$ & 0.01266 & 74.27857 \\
\hline 3.0142 & 54.1727 & 74.2951 & 74.2869 & 74.2809 & 74.2738 & 74.2696 & 74.2619 & $0.0162 \%$ & 0.01206 & 74.27803 \\
\hline 3.2835 & 57.5540 & 74.2951 & 74.2855 & 74.2804 & 74.2745 & 74.2687 & 74.2617 & $0.0161 \%$ & 0.01198 & 74.27765 \\
\hline
\end{tabular}

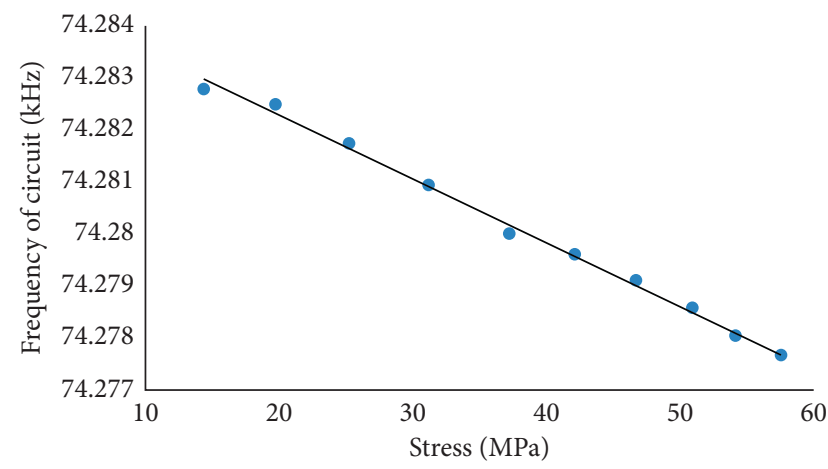

FIGURE 8: Relationship diagram between median frequency and median stress.

\section{Conclusion}

It is a challenging problem to detect the prestressing force of the structural steel strand in service concrete. The deformation of concrete, the relaxation of the prestressed steel strand, the corrosion of the steel strand, and the creep of concrete will cause the loss of prestress. However, the prestress loss has not been solved well, so it is important to detect the prestressed concrete structure effectively. The traditional method for detecting the prestressing force of the steel strand in the existing structure is complex, and the equipment that is used to obtain the prestressing force is expensive and inconvenient to carry. The vibration frequency of the oscillating circuit is used to detect the loss of prestress in the steel strand, which avoids the damage to the structure caused by the prestress detection and provides a timely and accurate method for detecting prestress.

The idea of the whole system is to connect the steel strand to the oscillating circuit, and the steel strand is equivalent to inductance in the circuit. The vibration frequency of the circuit is obtained by vibration, and the prestressing force in the steel strand can be obtained by calculation. A series of experimental data show that there is a certain relationship between the prestress of the steel strand and the frequency of oscillation. The inverse

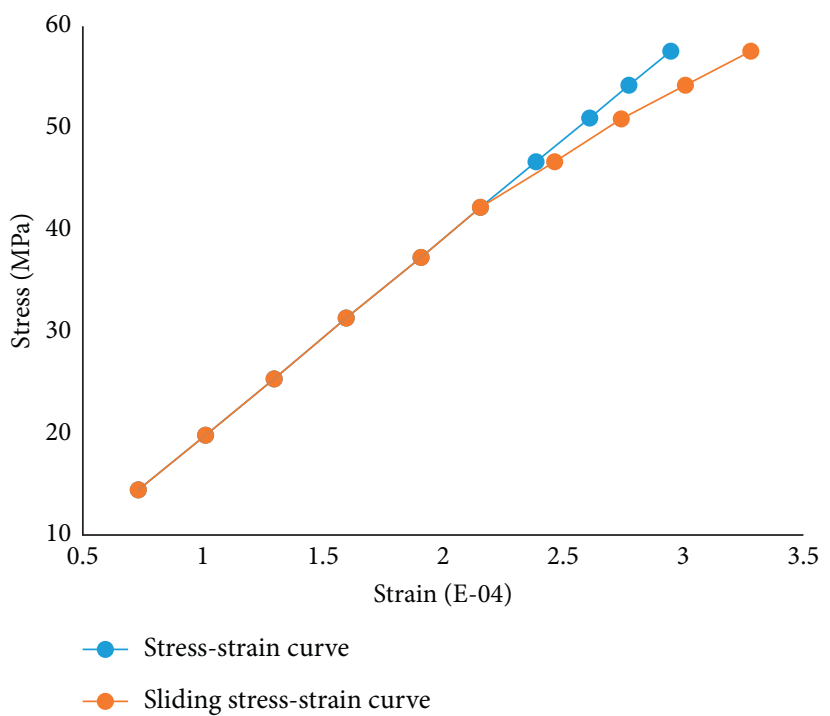

FIgURE 9: Relationship diagram between stress and strain.

proportion relationship between the stress and frequency is obtained by data analysis, which is consistent with the theoretical derivation of this paper. It is proved that the method of detecting the prestressing force in the steel strand by the oscillation frequency of the circuit is practicable. It is also verified the previous conjecture that there is a certain relationship between the electromagnetic force and the strand force.

Adopting the EMO circuit, the experiments have been greatly improved in measuring accuracy and range. The measuring force of the steel strand is closer to the actual situation. The frequency meter used in the experiment is in the range of $20-200 \mathrm{kHz}$, whose measuring range is larger than the original one. And the measurement accuracy is $0.001 \mathrm{kHz}$.

Compared with the traditional method, it is more convenient and feasible to measure the prestressing force of the steel strand by the oscillating circuit, and it can reflect the force of the steel strand without any damage to prestressed structures. 
Nevertheless, in the process of the steel strand, the experiment has failed to solve the rotation and frequency drift well. These are the problems that we have to deal with in the next step.

\section{Conflicts of Interest}

The authors declare that there are no conflicts of interest regarding the publication of this paper.

\section{Acknowledgments}

This work is jointly supported by the National Key Research and Development Program of China (2017YFC0806007), the Science and Technology Construction Project of Ministry of Transport of China (2015319814020), the Technology Innovation Project of Chongqing Social and People's Livelihood (CSTC2016SHMSZX30026), the Program for Innovation Team Building at Institutions of Higher Education in Chongqing (CXTDG201602013), the Urumqi Science and Technology Plan (Y161320008), the Scientific and Technological Research Program of Chongqing Municipal Education Commission (KJ1400321 and KJ1605202), the National Science Fund for Distinguished Young Scholars (51425801), and the National Natural Science Foundation of China (11372366 and 51508059).

\section{References}

[1] A. B. M. Abdullah, J. A. Rice, H. R. Hamilton, and G. R. Consolazio Gary, "An investigation on stressing and breakage response of a prestressing strand using an efficient finite element model," Engineering Structures, vol. 123, pp. 213-224, 2016.

[2] A. O. Abdelatif, J. S. Owen, and M. F. M. Hussein, "Modelling the prestress transfer in pre-tensioned concrete elements," Finite Elements in Analysis and Design, vol. 94, pp. 47-63, 2015.

[3] L. Z. Dai, L. Wang, J. R. Zhang, and X. H. Zhang, "A global model for corrosion-induced cracking in prestressed concrete structures," Engineering Failure Analysis, vol. 62, pp. 263-275, 2016.

[4] W. Velez, F. Matta, and P. Ziehl, "Acoustic emission monitoring of early corrosion in prestressed concrete piles concrete piles," Structural Control and Health Monitoring, vol. 22, no. 5, pp. 873-887, 2015.

[5] A. Appalla, M. K. ElBatanouny, W. Velez, and P Ziehl, "Assessing corrosion damage in posttensioned concrete structures using acoustic emission," Journal of Materials in Civil Engineering, vol. 28, no. 2, p. 04015128, 2016.

[6] J. Mangual, M. ElBatanouny, P. Ziehl, and F. Matta, "Corrosion damage quantification of prestressing strands using acoustic emission," Journal of Materials in Civil Engineering, vol. 25, no. 9, pp. 1326-1334, 2013.

[7] W. P. Zhang, X. G. Liu, and X. L. Gu, "Fatigue behavior of corroded prestressed concrete beams," Construction and Building Materials, vol. 106, pp. 198-208, 2016.

[8] B. Fernandes, M. Titus, D. K. Nims, A. Ghorbanpoor, and V. Devabhaktuni, "Field test of magnetic methods for corrosion detection in prestressing strands in adjacent box-beam bridges," Journal of Bridge Engineering, vol. 17, no. 6, pp. 984-988, 2012.
[9] R. Saiedi, M. F. Green, and A. Fam, "Behavior of CFRPprestressed concrete beams under sustained load at low temperature," Journal of Cold Regions Engineering, vol. 27, no. 1, pp. 1-15, 2013.

[10] X. M. Hou, W. H. Zheng, V. Kodur, and H. Y. Sun, "Effect of temperature on mechanical properties of prestressing bars," Construction and Building Materials, vol. 61, pp. 24-32, 2014.

[11] L. A. Caro, J. R. Marti-Vargas, and P. Serna, "Time-dependent evolution of strand transfer length in pretensioned prestressed concrete members," Mechanics of Time-Dependent Materials, vol. 17, no. 4, pp. 501-527, 2013.

[12] X. Yang, P. Zohrevand, A. Mirmiran, M. Arockiasamy, and W. Potter, "Comparative study of unbonded carbon fiber and steel strands in posttensioned pier caps," Journal of Composites for Construction, vol. 20, no. 1, p. 04015036, 2016.

[13] C. G. Lan, Z. Zhou, and J. P. Ou, "Monitoring of structural prestress loss in RC beams by inner distributed Brillouin and fiber Bragg grating sensors on a single optical fiber," Structural Control and Health Monitoring, vol. 21, no. 3, pp. 317-330, 2014.

[14] N. F. Grace, S. K. Rout, K. Ushijima, and M. Bebawy, "Performance of carbon-fiber-reinforced polymer stirrups in prestressed-decked bulb T-beams," Journal of Composites for Construction, vol. 19, no. 3, p. 04014061, 2015.

[15] P. A. Vanniamparambil, F. Khan, K. Hazeli et al., "Novel optico-acoustic nondestructive testing for wire break detection in cables," Structural Control and Health Monitoring, vol. 20, no. 11, pp. 1339-1350, 2013.

[16] H. M. Lee, S. W. Choi, D. J. Jung, and H. S. Park, "Analytical model for estimation of maximum normal stress in steel beam-columns based on wireless measurement of average strains from vibrating wire strain gages," Computer-Aided Civil and Infrastructure Engineering, vol. 28, no. 9, pp. 707717, 2013.

[17] H. S. Park, H. Y. Lee, S. W. Choi, and Y. Kim, "A practical monitoring system for the structural safety of mega-trusses using wireless vibrating wire strain gauges," Sensors, vol. 13, no. 12, pp. 17346-17361, 2013.

[18] S. Biswal and A. Ramaswamy, "Measurement of existing prestressing force in concrete structures through an embedded vibrating beam strain gauge," Measurement, vol. 83, no. 10, pp. 10-19, 2016.

[19] J. A. Paredes, S. Oller, and A. H. Barbat, "New tensioncompression damage model for complex analysis of concrete structures," Journal of Engineering Mechanics, vol. 142, no. 10, 2016. 


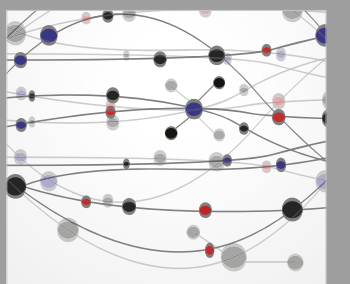

The Scientific World Journal
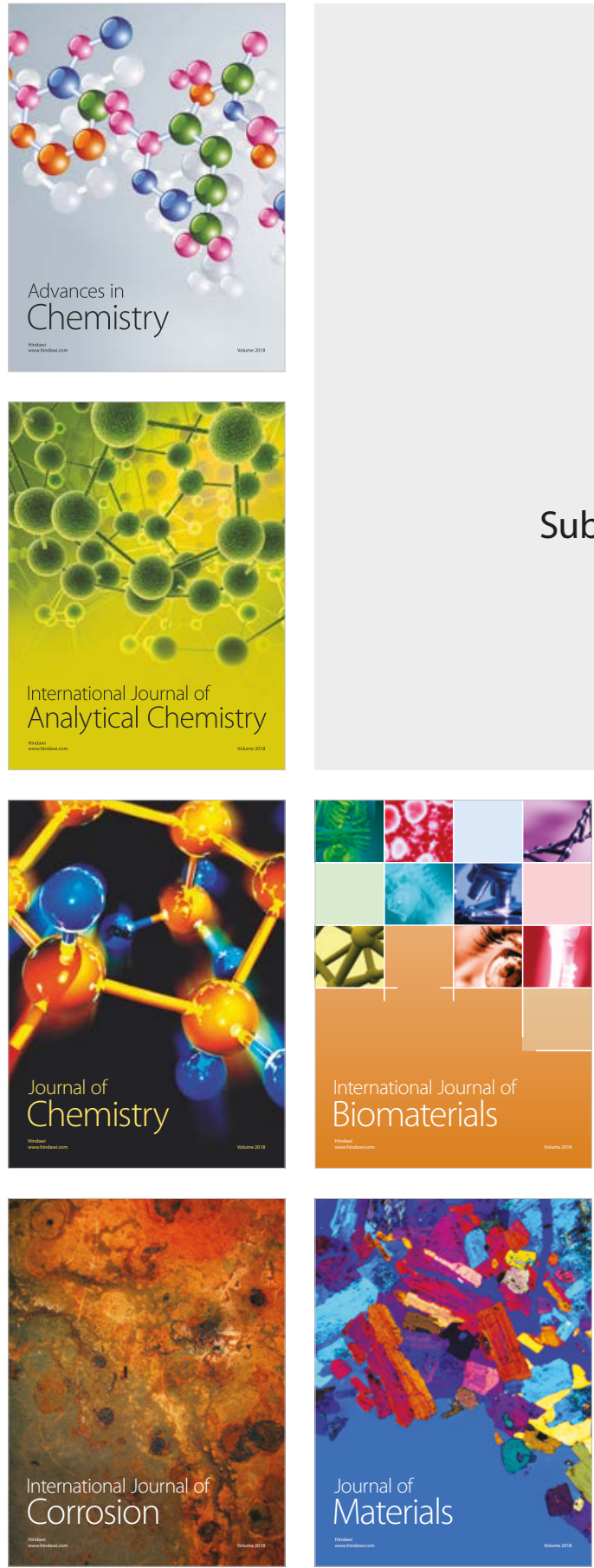

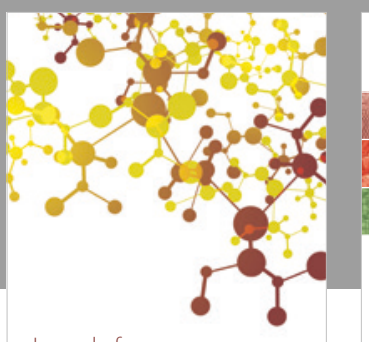

Journal of

Applied Chemistry
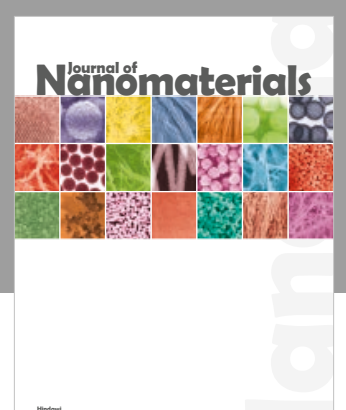

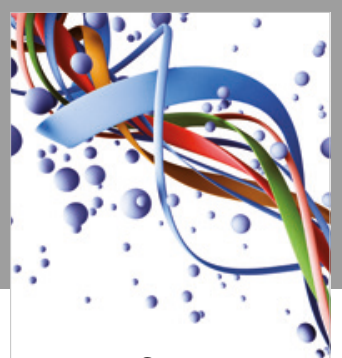

Scientifica

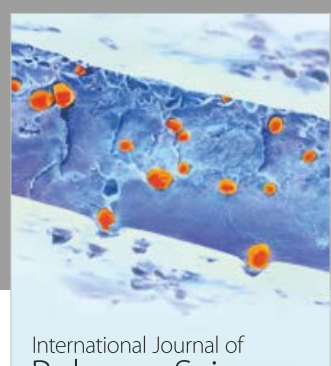

Polymer Science

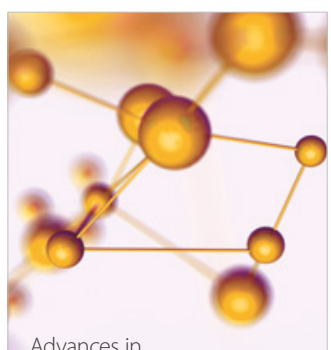

Physical Chemistry
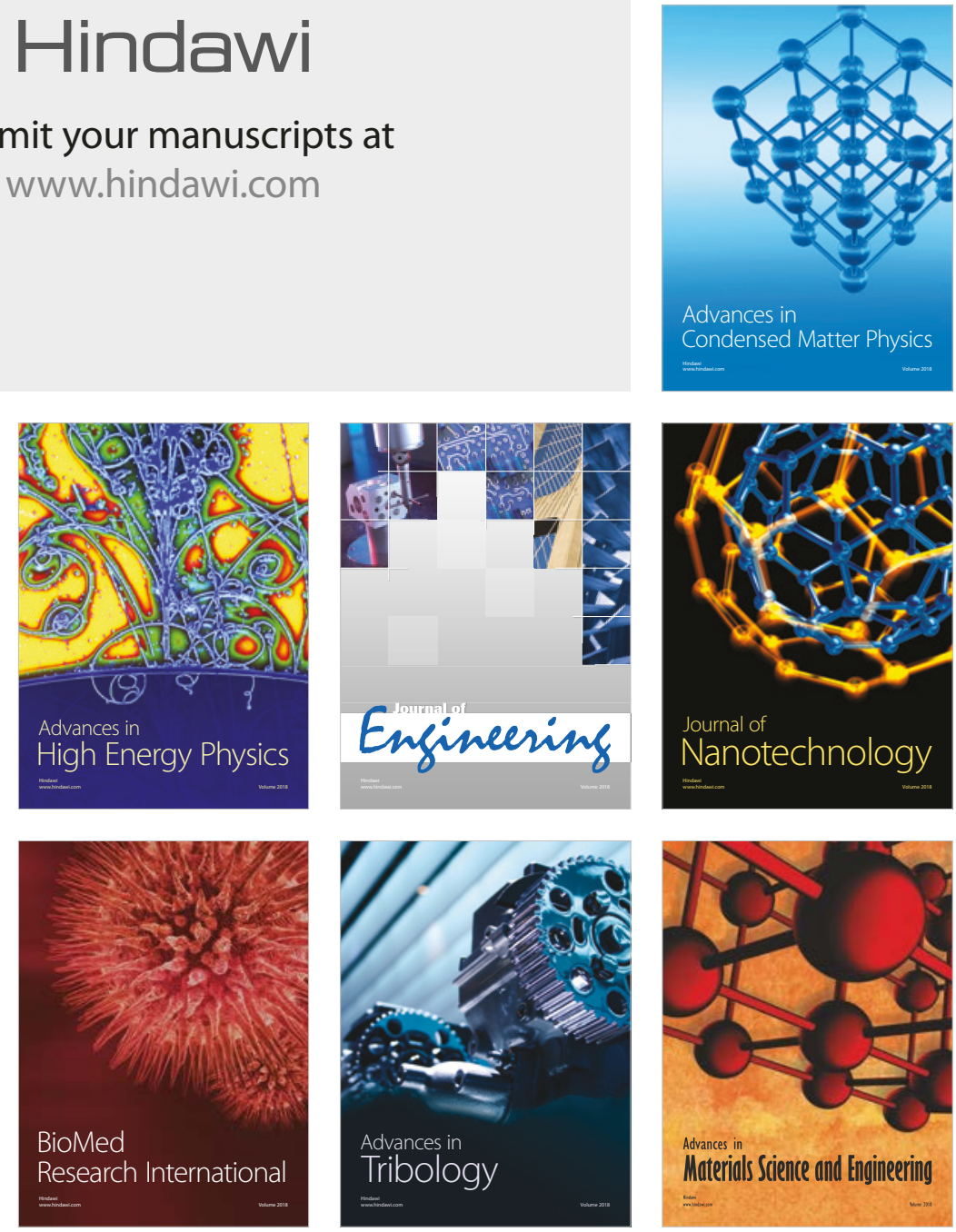